\title{
EKSTRAKSI ZAT WARNA DARI KULIT BUAH MANGGIS (Garcinia Mangostana L) DAN APLIKASINYA PADA BENANG TENUN BIMA
}

\author{
Sri Rahmawati ${ }^{1}$, Ruslan ${ }^{1}$, Agrippina Wiraningtyas ${ }^{1}$, Sry Agustina ${ }^{1}$ \\ ${ }^{1}$ Program Studi Pendidikan Kimia STKIP BIMA
}

\begin{abstract}
ABSTRAK
Kulit buah manggis sampai saat ini belum dimanfaatkan secara optimal dan masih dianggap sebagai limbah oleh masyarakat maupun penjual masih kurang dan bahkan dibuang begitu saja. Salah satu bahan yang dapat di gunakan untuk pembuatan zat warna alami yaitu dari kulit buah manggis (Garcinia mangostana L). Kandungan yang terdapat pada buah manggis antasionin yang menghasilkan warna merah, ungu, dan biru (Indra 2009). Tujuan penelitian ini adalah mengetahui pengaruh waktu pelarut terhadap ekstrak zat warna dari kulit buah manggis, mengetahui waktu optimum pada ekstrak zat warna kulit buah manggis dengan menggunakan metode maserasi, dan mengetahui pengaruh variasi waktu pelarut terhadap zat warna dari kulit buah manggis pada pewarnaan benabg bahan baku kain tenunan Bima. Ekstrak kulit buah manggis didapat dengan cara diekstraksi menggunakan metode maserasi dengan pelarut etanol waktu 1 jam, 2 jam, 3 jam, 4 jam, dan 5 jam. Ekstrak yang diperoleh kemudian diukur nilai absorbansinya menggunakan alat spektrofotometer UV-Vis pada rentang panjang gelombang 190-600 nm, serta digunakan untuk mewarnai benang tenunan. Hasil penelitian ini adalah variasi waktu pelarut etanol berperngaruh terhadap ekstrak zat warna dari kulit buah manggis dengan metode maserasi. Waktu optimum pelarut etanol untuk ekstrak zat warna dari kulit buah manggis dengan metode maserasi adalah waktu 4 jam yang menghasilkan nialai absorbansi 4.459. Dan variasi waktu pelarut etanol berpengaruh terhadap hasil warna pada bahan baku benang tenunan Bima.
\end{abstract}

Kata Kunci : Ekstraksi, Maserasi, Kulit Buah Manggis, Zat Warna, Benang Tenunan

\section{PENDAHULUAN}

Kulit buah manggis sampai saat ini belum dimanfaatkan secara optimal dan masih dianggap sebagai limbah oleh masyarakat maupun penjual masih kurang dan bahkan dibuang begitu saja. Kulit buah manggis sukar membusuk jika dibiarkan di udara bebas selama lebih dari 30 hari dan tidak akan mengalami degradasi sehingga dapat mencemari lingkungan. Hal ini dikarenakan kandungan kulit buah manggis yang sifatnya antioksidan dan antibacterial. Sehingga perlunya dilakukan penelitian dan inovasi pemanfaatan bahan alam sebagai pewarna alami. Pewarna alami merupakan zat warna yang berasal dari ekstraksi tumbuhan (seperti bagian daun, bunga, biji, hewan dan mineral). Salah satu bahan yang dapat di gunakan untuk pembuatan zat warna alami yaitu dari kulit buah manggis (Garcinia mangostana L). Kandungan yang terdapat pada buah manggis antasionin yang menghasilkan warna merah, ungu, dan biru (Indra 2009). Ekstraksi adalah suatu metode yang dapat mengeluarkan komponen tertentu dari zat padat atau zat cair dengan cara pelarutan (Mastuti, dkk., 2013). Salah satu metode ekstraksi adalah ekstraksi secara maserasi. Keuntungan menggunakan metode ini yaitu lebih sederhana dengan teknik merendam bahan selama beberapa jam dengan pelarut yang sesuai. Faktor-faktor yang mempengaruhi ekstraksi adalah suhu ekstraksi, waktu ekstraksi, perbandingan jumlah bahan terhadap pelarut, ukuran bahan, jenis pelarut, kadar (konsentrasi) pelarut dan kecepatan proses pengadukan. Faktor-faktor tersebut nantinya akan menentukan seberapa banyak ekstrak dapat diambil dari suatu sampel (Yuniwati, dkk., 2012). Ekstraksi juga divariasikan agar didapatkan waktu ekstraksi optimum, karena pada waktu ekstraksi optimum interaksi antara zat terlarut dengan pelarut akan semakin baik, sehingga banyak ekstrak yang akan terambil (Siahaan, dkk, 2014). Hasil dari ekstrak kulit buah 
manggis ini akan diaplikasikan pada kain tenun bima Kerajnan tenun Bima ini sangat berbeda dari kerajinan tenun yang dihasilkan oleh daerah lain selain dari karakteristik kain yang dingin dan lembut juga dari makna simbolik dari motif yang ada pada kain tenun tembe nggoli. Kerajinan tenun Tembe Nggoli memiliki pesan moral kehidupan yang tersirat dalam bentuk makna simbolik.

Berdasarkan latar belakang di atas, maka pada penelitian ini akan dilakukan ekstraksi zat warna dari kulit buah manggis dan aplikasinya pada benang tenunan Bima, dengan metode maserasi. Pelarut yang digunakan adalah etanol dengan variasi waktu 1,2,3,4 dan 5 jam. Untuk mengukur absorbansi ekstrak zat warna hasil ekstraksi menggunakan spektrofotometer UV-Vis.

\section{METODE}

\section{Alat dan Bahan}

Adapun alat yang diperlukan dalam penelitian ini adalah baskom, blender (penghalus), sendok, gelas ukur, labu ukur ukuran $100 \mathrm{~mL}$, pipet volum, tabung reaksi, neraca analitik gunting, batang pengaduk, beker, corong, labu erlemeyer, thermometer, kompor, toples, mangkuk kaca dan Spektrofotometer UV-Vis. Sedangkan bahan yang diperlukan dalam penelitian ini adalah kulit buah manggis (Garcinia Mangostana L), aquades, etanol 96\%, kertas saring, kertas lebel, plastic, kapur tohor $\left(\mathrm{CaCO}_{3}\right)$, tawas, tunjung $\left(\mathrm{feSO}_{4}\right)$, dan soda abu.

\section{Prosedur Penelitian}

Prosedur penielitian ini dilakukan melalui beberapa tahap kegiatan sebagai berikut :

\section{Persiapan Sampel}

Sampel diambil dari pasar Amahami Kota Bima, berupa kulit buah manggis. Kulit manggis dipotong kecil-kecil dan dibersihkan untuk menghilangkan bendaa sing yang menempel, kemudian ditumbuk/diblender agar bisa di ekstraksi.

Tahap Ekstraksi Zat Warna dari Kulit Manggis dengan Variasi Waktu Pelarut Etanol

Sampel kulit buah manggis diekstrak di timbang sebanyak 50 gram. Kemudian dimasukan kedalam mangkuk kaca masing-masing 10 gram lalu ditambahkan masing-masing $100 \mathrm{~mL}$ pelarut etanol dengan variasi waktu 1 jam, 2 jam, 3 jam, 4 jam dan 5 jam pelarut dan zat terlarut ini diekstraksi dengan metode maserasi pada suhu ruang dengan lama waktu yang di tentukan sehingga didapatkan lima larutan dengan ariasi waktu yang berbeda-beda. Setelah ekstrak tercampur dengan maserasi yang ditentukan pelarut disaring menggunakan kertas saring. Hasil penyaringan berupa residu dan fitrat. Pada penelitian ini fitrat yang akan dimanfaatkan untuk tahap berikutnya.

Tahap selanjutnya dilakukan uji yaitu uji fisik dilihat dengan melihat langsung warna hasil ekstrak. Sedangkan untuk uji kimia yaitu pengujian menggunakan spektrofotometer UVVis dengan panjang gelombang 200-600 nm.

\section{Tahap pewarnaan Benang Bahan Baku Tenunan Bima Dari Hasil Ekstraksi Zat Warna dari Kulit Buah Manggis \\ Tahap Mordanting}

Siapkan benag tawas dan soda abu, timbang tawas sebanyak 12 gr untuk 2 liter air, ke mudian timbang soda abu sebanyak 4 gram untuk 2 liter air. Setelah itu untuk proses perebusan mula-mula larutkan tawas dengan setengah 1 liter air, setelah tawas larut daam air, kemudian ditambah kekukarangan airnya sebanyak 1 liter air. Lalu setelah mencapai suhu $60{ }^{\circ} \mathrm{C}$ tambahkan soda abu dan 2 liter air aduk dan tunggu soda abu tercampur dengan air. Setelah semua sudah tercampur, kecilkan api dan masukan benang pada larutan dengan posisi benang stabil $60{ }^{\circ} \mathrm{C}$ dan tunggu hingga \pm 1 jam setengah. Setelah itu matikan konpor dan biarkan 
benang pada rendaman selama semalam. Keesokan harinya baru ditiriskan dibilas bersih dan di jemur sampai kering

\section{Tahap Pewarnaan Benang}

Rendam benang pada zat warna dengan 5 variasi waktu yang telah ditentukan angkat dan jemur benang hingga kering.

\section{Tahap Fiksasi}

Siapkan larutan fiksator tawas, tunjung dan kapur tohor, rendam benang \pm 2 menit, benang dibolak-balik agar merata, setelah 2 menit angkat benang, peras dan jemur hingga kering.Tahap selanjutnya dilakukan uji, yaitu uji fisik dengan melihat langsung warna yang dihasilkan pada benang.

\section{HASIL dan PEMBAHASAN}

\section{Hasil Ekstraksi Zat Warna dari Kulit Buah Manggis (Garcinia Mangostana L.) dengan Metode Maserasi Variasi Waktu Pelarut Etanol \\ Data Uji Fisik}

Pada data uji fisik didapatkan hasil berupa ekstrak dari kulit buah manggis berwarna coklat biskue untuk waktu 1 jam, berwarna blanchedalmond untuk waktu 2 jam, berwarna blanchedalmond untuk 3 jam, berwarna blandhedalmond 4 jam, dan warna blanchedalmond 5 jam. Kelima warna tersebut merupakan turunan dari warna coklat.

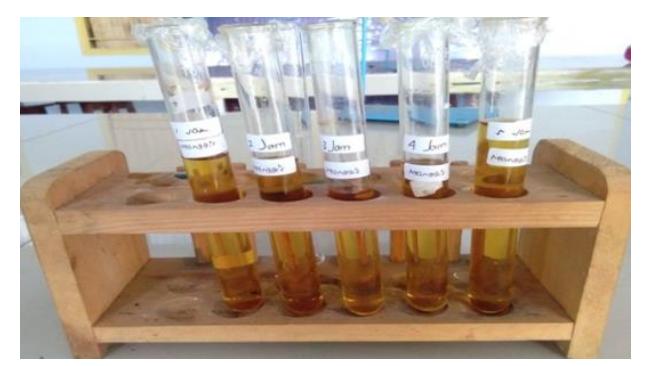

Gambar 1. Ekstrak Kulit Buah Manggis pada variasi waktu

\section{Data Absorbansi Ekstrak}

Pada data absorbansi ekstrak didapatkan nilai absorbansi sebagai berikut:

Tabel 1. Data Nilai Absorbansi Tertinggi Variasi Waktu Pelarut Etanol

\begin{tabular}{|c|c|c|c|c|}
\hline No. & $\begin{array}{c}\text { Waktu } \\
\text { Ekstrak }\end{array}$ & Warna Ekstrak & $\begin{array}{c}\text { Panjang } \\
\text { Gelombang }\end{array}$ & $\begin{array}{c}\text { Absorbansi } \\
(\mathrm{A})\end{array}$ \\
\hline 1. & $1 \mathrm{jam}$ & Coklat biskue & $230 \mathrm{~nm}$ & 3.940 \\
\hline 2. & $2 \mathrm{jam}$ & $\begin{array}{c}\text { Coklat } \\
\text { blanhedalmon }\end{array}$ & $230 \mathrm{~nm}$ & 4.171 \\
\hline 3. & $3 \mathrm{jam}$ & $\begin{array}{c}\text { Coklat } \\
\text { blandhedalmond }\end{array}$ & $224 \mathrm{~nm}$ & 4.272 \\
\hline 4. & $4 \mathrm{jam}$ & $\begin{array}{c}\text { Coklat } \\
\text { blandhedalmond }\end{array}$ & $230 \mathrm{~nm}$ & 4.459 \\
\hline 5. & $5 \mathrm{jam}$ & $\begin{array}{c}\text { CokLat } \\
\text { blandhedalmond }\end{array}$ & $230 \mathrm{~nm}$ & 4.279 \\
\hline
\end{tabular}




\section{Hasil Pewarnaan Benang Bahan Baku Kain Tenun Bima dengan Zat Warna Kulit Buah Manggis Garcinia Mangostana L Variasi Waktu Pelarut Etanol}

Dari hasil penelitian dapat diketahui bahwa kulit buah manggis (Garcinia Mangostana L) dapat mewarnai benang tenunan Bima dengan warna cokelat yang dihasilkan oleh pigmen anthosianin seperti cyaniding-3-sophoroside dan cyaniding -3-glucoside (warid, 2007). Berikut warna secara fisik benang hasil pewarnaan menggunakan zat warna dari kulit buah manggis dengan variasi waktu 1 jam, 2 jam, 3 jam, 4 jam, dan 5 jam dengan pelarut etanol.

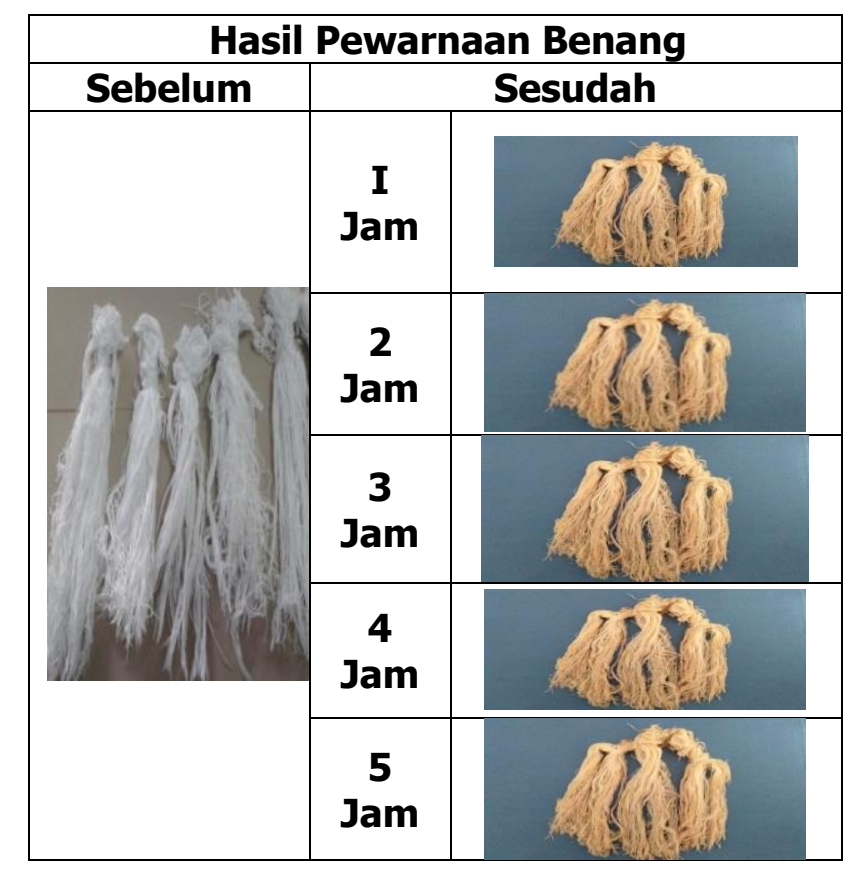

Gambar 2. Hasil warna benang menggunakan ekstrak kulit buah manggis dengan variasi waktu

\section{Pembahasan \\ Ekstraksi Zat Warna dari Kulit Buah Manggis (Garcinia Mangostana L)}

\section{Tahap Preparasi Sampe}

Proses pembersihan sampel kulit buah manggis (Garcinia Mangostana L) dilakukan dengan cara mencucinya dengan air mengalir untuk menghilangkan benda asing yang menempel agar tidak mengganggu ekstrak yang dihasilkan (Rohmaniyah, 2016). Selanjutnya, sampel dipotong kecil-kecil untuk mempercepat proses pengeringan. Proses pengeringan bertujuan untuk menghilangkan kadar air yang terkandung dalam sampel. Sampel yang telah kering diblender sampai halus agar lebih mudah memecah dinding membran sel sehingga memaksimalkan proses ekstraksi (Koirewoa, dkk. 2008).

Ekstraksi zat warna dari kulit buah manggis (Garcinia Mangostana L) dengan berbagai variasi waktu 
Proses awal ekstraksi yang dilakukan dalam penelitian ini adalah ekstraksi zat warna dari kulit buah manggis (Garcinia Mangostana L). dengan memvariasikan waktu ekstraksi dengan metode maserasi. Metode maserasi dipilih karena metode ini dapat menghasilkan ekstrak yang baik dan dilakukan tanpa melalui proses pemanasan sehingga dapat mengurangi kerusakan komponen aromatic (Wiraningtyas, dkk., 2019). Menurut Mastuti, dkk. (2013), faktor-faktor yang berpengaruh pada proses ekstraksi, salah satunya adalah waktu Semakin lama waktu ekstraksi maka akan memberikan hasil yang diperoleh lebih besar, karena kontak antara pelarut dan bahan yang diekstraksi juga akan semakin lama sehingga akan menyebabkan pelarut semakin diperkaya oleh solute

Tabel 1 menunjukkan bahwa terdapat perbedaan nilai absorbansi dari tiap hasil ekstrak zat warna dengan variasi waktu ekstraksi. Untuk ekstrak 1 jam menghasilkan nilai absorbansi sebesar 3,940 $(\lambda=230)$, untuk ekstrak 2 jam sebesar 4,171 $(\lambda=230)$, untuk ekstrak 3 jam sebesar 4,272 $(\lambda=224)$, untuk ekstrak 4 jam sebesar 4,459 $(\lambda=230)$, dan untuk ekstrak 5 jam sebesar 4,279 $(\lambda=230)$. Terjadi peningkatan nilai absorbansi pada ekstrak 1 jam, 2 jam, 3 jam, dan 4 jam sesuai dengan teori yang menyatakan bahwa semakin lama waktu ekstraksi, maka semakin banyak ekstrak yang akan didapat Awwaliyah (2019). Namun terjadi penurunan nilai absorbansi pada ekstrak 5 jam, hal tersebut disebabkan oleh komponen-komponen yang terdapat dalam bahan jumlahnya terbatas dan pelarut yang digunakan mempunyai batas kemampuan untuk melarutkan bahan yang ada, sehingga walaupun waktu ekstraksi diperpanjang. Solute yang ada didalam bahan sudah tidak ada Dian Yulianti (2014). Nilai absorbansi tertinggi dihasilkan oleh ekstrak 4 jam.

\section{Pewarnaan Benang Bahan Baku Kain Tenunan Bima dengan Zat Warna Daun Jati Muda Variasi Konsentrasi Pelarut Etanol}

\section{Tahap Mordanting}

Pewarnaan benang dilakukan dengan cara dimordanting terlebih dahulu. Proses mordanting bertujuan untuk mensterilkan benang dari unsur logam dan lemak, mengembangkan serat benang sehingga mudah diserap zat warna alam (Lestari, dkk., 2018). Benang yang digunakan adalah benang berwarna putih dengan massa masing-masing 7,5 gram untuk tiap variasi waktu. Hasil benang dari proses mordanting dapat dilihat dalam gambar berikut:

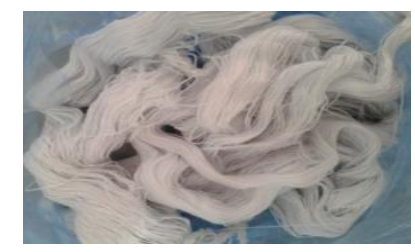

Gambar 3 : Benang Sebelum dan Sesudah Dimordanting a.Sebelum dimordanting

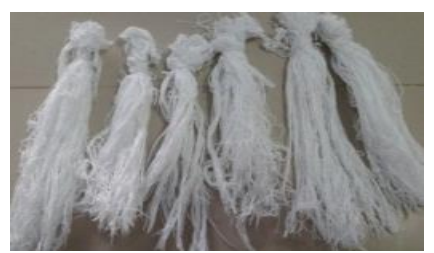

b. Sesudah dimordanting

\section{Tahap Pewarnaan Benang}

Pewarnaan benang menggunakan bahan alam ekstrak kulit buah manggis dilakukan dengan cara direndam selama 15 menit. Tujuan dari proses perendaman ini agar terjadi penyerapan zat warna kedalam benang (Azizah, 2018). Hasil yang diperoleh dari proses pewarnaan ini dapat dilihat pada tabel 4.3. Berdasarkan tabel 4.3 di atas dapat dilihat perubahan warna yang dihasilkan dari proses perendaman benang dengan ekstrak kulit buah manggis. Benang yang awalnya berwarna putih, mengalami perubahan warna menjadi warna 
cokelat. Tidak terjadi gradasi warna yang mencolok antara variasi waktu yang 1 jam, 2 jam, 3 jam, 4 jam, dan 5 jam karena warna yang dihasilkan secara umum terlihat berwarna cokelat. Hal ini menunjukkan bahwa variasi waktu perendaman tidak memberikan pengaruh yang signifikan terhadap proses pewarnaan benang dari ekstrak kulit buah manggis.

\section{Tahap Fiksasi}

Fiksasi merupakan proses akhir pada penelitian ini. Fiksasi bertujuan untuk mengunci warna, agar warna memiliki ketahanan luntur yang baik (Thomas, dkk., 2013). Proses fiksasi menggunakan tiga bahan, yaitu tawas, tunjung, dan kapur. Ketiga bahan tersebut dipakai untuk merendam benang dalam wadah berbeda selama 15 menit. Pada proses fiksasi terjadi perubahan warna benang dari ketiga bahan yang digunakan, sebagai berikut:

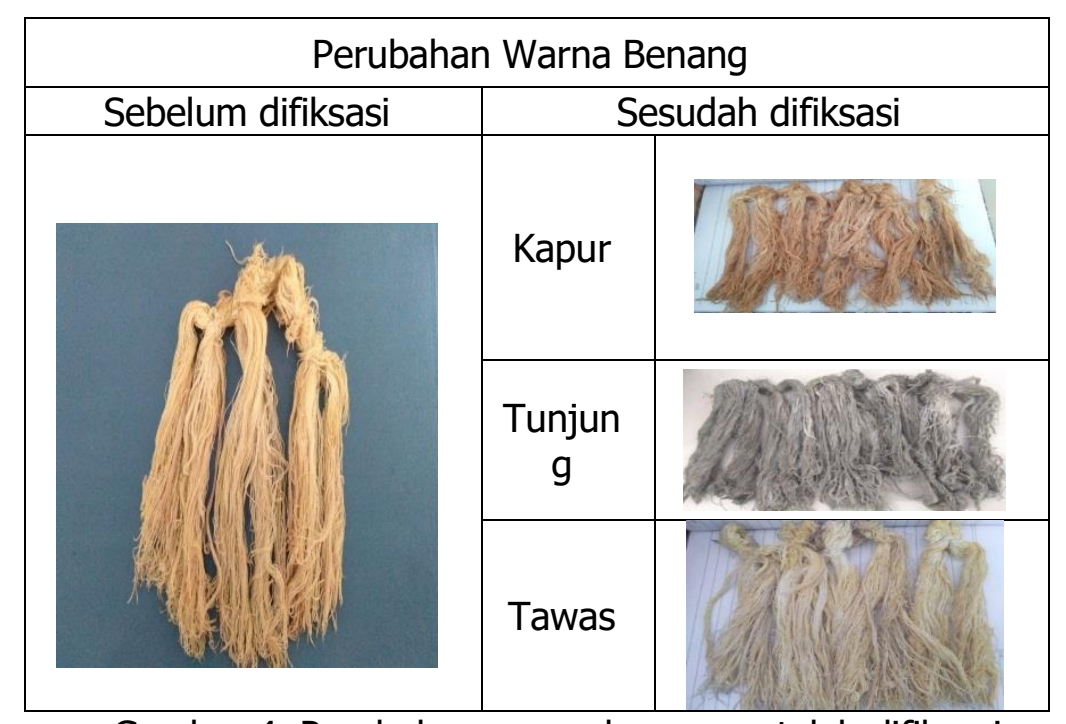

Gambar 4. Perubahan warna benang setelah difiksasi

Pada gambar 4. dapat dilihat perubahan warna setelah proses fiksasi. Untuk Kapur warna benang berubah menjadi cokelat gelap, diaman warna sebelum fiksasi menggunakan kapur itu berwarna cokelat terang, ini disebapkan dipengaruhi oleh kandungan senyawa Ca2+ yang bereaksi dengan ekstrak kulit buah manggis sedangkan untuk tawas berubah menjadi kuning, dipengaruhi oleh senyawa kimia yang terdapat dalam tawas Al3+ yang bereaksi dengan ekstrak kulit buah manggis (Septiadini \& Muflihati, 2019). Kemudian untuk bahan fiksasi tunjung berubah warna menjadi abu-abu, hal ini disebabkan kandungan besi yang terdapat dalam tunjung dan adanya proses oksidasi membuat warna yang dihasilkan pada benang menjadi tua (Fardhyanti dan Ria, 2015).

\section{KESIMPULAN}

Variasi waktu pelarut etanol berpengaru terhadap ekstrak zat warna dari kulit manggis (Garcinia Mangostana L) dengan metode maserasi. Waktu optimum pelarut etanol untuk ekstrak zat warna dari kulit manggis (Garcinia Mangostana L) dengan metode maserasi adalah waktu 4 jam yang menghasilkan nilai absorbansi 4,459. Variasi waktu ekstraksi pelarut etanol berpengaruh terhadap hasil warna pada bahan baku benang tenunan bima. 


\section{DAFTAR PUSTAKA}

Azizah, Wahidatun, N. (2018). Pengaruh Jenis Zat Fiksasi Terhadap Kualitas Pewarnaan Kain Mori Primissima dengan Zat Warna Euphorbia. Yogyakarta: Uneversitas Negeri Yogyakarta.

Fardyanti, D. S. \& Ria,. D. R (2015). Pemungutan Brazillin dari Kayu Secang (Caesilpinia Sappan L) dengan Metode Maserasi dan Aplikasinya Untuk Pewarnaan Kain. Jurnal Bahan Alam Terbarukan, 4 (1): 6-13

Indra, D. 2009. "Pewarna Alami dari Buah Manggis", http://www.pikiranrakyat.com/arsip/kampus.html

Lestari, A. A., Evy, W., \& Yeni, M (2018). Pemanfaatan Tumbuhan Penghasil Warna Alami Untuk Tenun Ikat Oleh SuKU Dayak Iban Di Dusun Takalong dan Dusun Kalawik Kapuas Hulu Kalimantan Barat.Jurnal Hutan Lestari, 6 (4): 837-847

Mastututi, E., Winaputri, M. G., dan Harlyandi, P. (2013). Ekstraksi Zat Warna Alami Kelopak Bunga Rosella dengan Pelarut Etanol.Ekuilibirium, 12 (2):49-53

Rohmaniyah, M. (2016). Uji Antioksidan Ekstrak Etanol 80\% dan Fraksi Aktif Rumput Bambu (Lophatherum gracile Brongn) Menggunakan Metode DPPH serta Identifikasi Senyawa Aktifnya. Malang: UIN Maulana Malik Ibrahim.

Siahaan, L. O., Hutapea, E. R., dan Tambun, R. (2014). Ekstraksi Pigmen Antosianin dari Kulit Rambutan (Nephelium lappaceum) dengan Pelarut Etanol. Jurnal Teknik Kimia USU, 3 (3): 32-38.

Wiranigtyas, A, Ruslan, Sry, Agustina, \& Uswatun, H. (2019). Penentuan Nilai Sun Protection Factor (SPF) dari Ekstrak Kulit Bawang Merah. Jurnal Redoks, 4 (01): 34-43

Yuniwati, M., Kusuma, A. W., dan Yunanto F. (2012). Optimasasi Kondisi Proses Ekstraksi Zat Pewarna dalam Daun Suji dengan Pelarut Etanol. Yogyakarta: Prosiding Seminar Nasional Aplikasi Sains dan Teknologi (SNAST). 